\title{
Assessment of the Excavation Damaged Zones in the Surrounding Rock of an Underground Powerhouse under High In Situ Stress Using an Acoustic Velocity Detecting Method
}

\author{
Liguo Zhang, ${ }^{1,2}$ Dong Wang, ${ }^{1}$ and Jiaxing Dong $\mathbb{D}^{3}$ \\ ${ }^{1}$ College of Mining, Liaoning Technical University, Fuxin, Liaoning 125105, China \\ ${ }^{2}$ Yunnan Minbao-Kungong Blasting Engineering Co., Ltd., Kunming, Yunnan 650093, China \\ ${ }^{3}$ Faculty of Electric Power Engineering, Kunming University of Science and Technology, Kunming, Yunnan 650500, China
}

Correspondence should be addressed to Jiaxing Dong; dong1986@kust.edu.cn

Received 6 January 2020; Revised 13 June 2020; Accepted 17 June 2020; Published 4 July 2020

Academic Editor: Hayri Baytan Ozmen

Copyright (c) 2020 Liguo Zhang et al. This is an open access article distributed under the Creative Commons Attribution License, which permits unrestricted use, distribution, and reproduction in any medium, provided the original work is properly cited.

Excavation damaged zones (EDZs) in deeply buried underground powerhouse have become major obstacles to design and support, which potentially threaten safety and stability and increase construction and support costs. In this study, investigations of the EDZs were performed by applying an acoustic velocity detecting method in Houziyan hydropower project, southwest of China. A total of 38 testing boreholes distributed in high sidewalls of the main powerhouse were carried out, and corresponding 153 curves were obtained and analyzed. Then, EDZs were divided into highly damaged zone (HDZ), slightly damaged zone (SDZ), and excavation influence zone (EIZ), respectively. Furthermore, we classified the wave velocity curves into four categories: type I, type II, type III, and type IV. EDZs were qualitatively assessed based on the curve categories; in addition, we used a qualitative assessment method, which mainly involved an index of damage degree named D. The assessment results show that HDZ, but not SDZ, was significantly asymmetrically distributed in the upstream (average depth of $4.1 \mathrm{~m}$ ) and downstream (average depth of $7.5 \mathrm{~m}$ ) high sidewalls; in partial areas, depth of HDZ exceeded the length of designed rock bolts, which indicates that rock bolts cannot restrain crack development and EDZs evolution. Generally, EDZs distribution was consistent with deformation and failure phenomena distribution; compared to the field failure phenomena, the assessment results were reliable and reasonable. Finally, EDZs formation mechanism was discussed, and it can be concluded that the relatively large intermediate principal stresses $\sigma_{2}$ were a critical driving factor of the EDZs evolution.

\section{Introduction}

With rapid economic development and increasing huge demand for energy, more and more underground structures such as deep transportation tunnels and mining roadways are being constructed or planned. Meanwhile, myriads of large-scale underground hydropower stations have been or are being constructed in Southwest China, such as Jinping I, Dagangshan, Xiluodu, Guandi, Wudongde, Houziyan, Shuangjiangkou, Baihetan, Laxiwa, and Lianghekou [1-9]. The underground powerhouses of these projects always feature high sidewalls, large spans, and complex geological conditions; some powerhouses are positioned in the high in situ stress zone. For instance, the excavation dimensions of the main underground powerhouse at the Dagangshan project located in the Dadu River are $226.6 \mathrm{~m}$ in length, $30.8 \mathrm{~m}$ in width, and $74.3 \mathrm{~m}$ in height [4]. The excavation dimensions of the main underground powerhouse at the Lianghekou project constructed on the Yalong River are $275.9 \mathrm{~m} \times 28.4 \mathrm{~m} \times 66.8 \mathrm{~m}$ (length $\times$ width $\times$ height, respectively) [6]. The excavation dimensions of the main underground powerhouse at the Xiangjiaba project constructed on the Jinsha River are $255.4 \mathrm{~m} \times 33.4 \mathrm{~m} \times 85.2 \mathrm{~m} \quad$ (length $\times$ width $\times$ height, respectively) [10]. The powerhouse of the Jinping I hydropower station located in the Yalong River was positioned in the high in situ stress zone; the magnitudes of maximum principal stress $\left(\sigma_{1}\right)$ were approximately $20.0-35.7 \mathrm{MPa}$, the second principal stress $\left(\sigma_{2}\right)$ magnitudes were approximately $10.0-25.0 \mathrm{MPa}$, and 
the minimum principal stress $\left(\sigma_{3}\right)$ magnitudes were approximately 4.0-12.0 MPa [5]. The Jinping II hydropower station has four parallel headrace tunnels, with a length of $16.7 \mathrm{~km}$ per tunnel, average buried depth of about $1500-2000 \mathrm{~m}$, and maximum depth of $2525 \mathrm{~m}$ [11]. The powerhouse of Laxiwa hydropower project located on Yellow River was positioned in the high in situ stress zone; the ranges of the maximum, intermediate, and minimum principle stresses were in the range of 19.1 to $29.7 \mathrm{MPa}, 12.6$ to $20.6 \mathrm{MPa}$, and 5.7 to $13.1 \mathrm{MPa}$, respectively [8]. Liu et al. reported that the spalling failure of local surrounding rock occurred frequently in the excavation of the first layer of the left and right powerhouse of Baihetan hydropower project [9].

Due to the increase of buried depth, with various and multiple geological structures, many failure phenomena such as rock bursts, collapse, cracks, spalling, unloading rebound-induced dislocations, and shotcrete layer cracking frequently occurred in the mentioned underground powerhouses subject to excavation. For instance, large displacements caused excavations to stop in Jinping I and Houziyan projects $[2,6,12]$. In addition, recovery after collapse in the regions of $\beta_{80}$ diabase dikes in Dagangshan projects took 18 months, which delayed construction and resulted in substantial economic losses $[4,6]$. Thus, the stability of underground caverns subjected to excavation plays a critical role in engineering safety.

Recently, considerable efforts have been made to assess the stability of the underground structures subjected to excavation, including characteristics of surrounding rock mass, excavation damaged zone (EDZ), and displacement prediction by using the field survey and measurement, laboratory testing, and numerical analysis [11-24]. For example, Zhu et al. [25] obtained the formulae to predict the displacements of the sidewalls of the underground caverns. Fei et al. [26] investigated the stability of underground caverns in six representative hydropower stations and obtained the correlation between the stress-strength ratio of the rock and the average and maximum displacements, respectively. Siren et al. [27] distinguished the constructioninduced excavation damage zone $\left(\mathrm{EDZ}_{\mathrm{CI}}\right)$ and stress-induced excavation damage zone $\left(\mathrm{EDZ}_{\mathrm{SI}}\right)$ based on in situ measurement and the ground penetrating radar (GPR) investigation data in the Äspö Hard Rock Laboratory (HRL). Li et al. [5] presented the extents and evolution of the EDZ in underground powerhouse of Jinping I project; the typical EDZs were graded as highly excavation damaged zone (HDZ), excavation damaged zone (EDZ), and excavation distributed zone (EdZ). Yan et al. [11] concluded that one of the main contributors to an EDZ is the in situ stress transient redistribution, and the blasting excavation-induced damage zone from the excavation surface to surrounding rock mass was divided into inner damage zone and outer damage zone. Tao et al. [28] investigated the EDZ around roadways in a lead-zinc mine in Guangzhou of China through a seismic velocity method and theoretical calculation.

Obviously, accurate estimation of the damage extent and intensity is required to ensure the stability of the surrounding rock mass after excavation. Recently, in situ measurement techniques such as multiple position extensometers, acoustic emission (AE) monitoring, microseismic (MS) monitoring, ground penetrating radar (GPR), resistivity and acoustic tomography, borehole expansion tests, borehole television (TV), and hydraulic tests are used to assess the EDZs around several excavation sites [5, 28-34]. In fact, in most hydropower projects in China, the acoustic velocity detecting method has been widely used in engineering practice for assessment of EDZs, because of its accuracy and efficiency. However, publications rarely concentrated on the quantitative assessment methods of EDZ in the large-scale and deeply buried underground caverns. In this study, an acoustic velocity testing was implemented in the main underground powerhouse of Houziyan hydropower project, which was constructed in the Dadu River, Sichuan Province, Southwest China. After using acoustic waves and borehole TV techniques, acoustic wave curves in different areas were classified into four types, and quantitative estimation of EDZs was carried out. Furthermore, EDZs around powerhouse caverns were graded as Highly Damaged Zone (HDZ), Slightly Damaged Zone (SDZ), and Excavation Influence Zone (EIZ) according to the damage degree. Meanwhile, the evolutions of EDZs in typical area throughout the excavation of the underground powerhouse were revealed.

\section{Project Background}

2.1. Underground Powerhouse Layout. The Houziyan hydropower station is the ninth hydropower project constructed on the Dadu River. It is located approximately $47 \mathrm{~km}$ from Danba County, $89 \mathrm{~km}$ from Luding County, and $402 \mathrm{~km}$ from Chengdu, Sichuan Province, China (see Figure 1). The large-scale underground powerhouse cavern group at the Houziyan hydropower station (see Figure 2) mainly includes four diversion tunnels, the main powerhouse, four tunnels that connect the omnibus bars of each set with the main transformer, the main transformer chamber, the tailrace surge chamber, and two tailrace tunnels.

Three main caverns (from upstream to downstream sidewalls: main powerhouse, transformer chamber, and tailrace surge chamber) are arranged in parallel. The largescale underground cavern is positioned along a rightflanking mountain at vertical depths of $400-600 \mathrm{~m}$ and at horizontal depths of $280-510 \mathrm{~m}$. The minimum vertical and horizontal depths of the main powerhouse are approximately $380 \mathrm{~m}$ and $250 \mathrm{~m}$, respectively. The excavation dimensions of the main powerhouse are $219.5 \mathrm{~m}$ in length, $29.2 \mathrm{~m}$ in width, and $68.7 \mathrm{~m}$ in height. The thickness of the rock pillars between the main transformer chamber and the main powerhouse is $45.0 \mathrm{~m}$. The underground powerhouse caverns were constructed using a conventional drill and blast method. The main powerhouse was excavated using 9 benches. The specific stratified excavation scheme of the main powerhouse is shown in Figure 3. The construction schedule for the main powerhouse was completed until May 23,2014 . In particular, the upstream sidewall of the main powerhouse deformed by approximately $100 \mathrm{~mm}$ in July 2013 and caused the excavation to stop for more than 2 


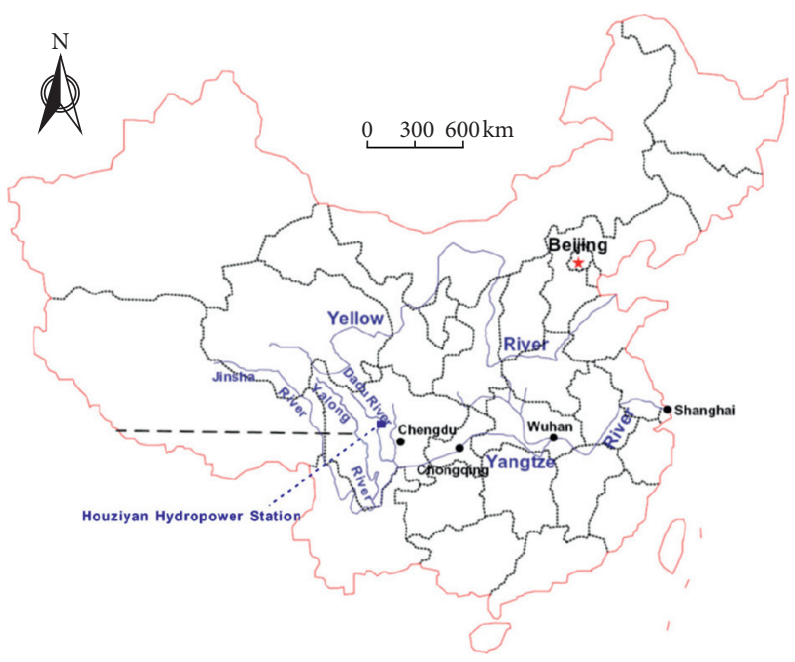

Figure 1: Regional map of Houziyan hydropower station.

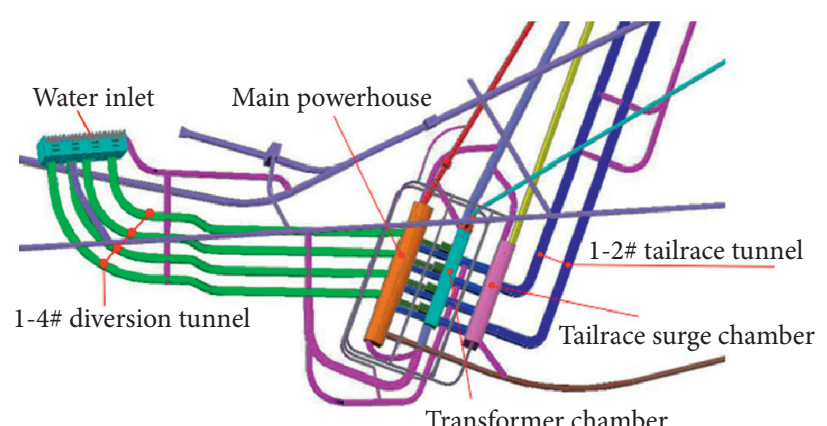

FIgURE 2: Layout of the underground cavern group at the Houziyan hydropower station.

(a)
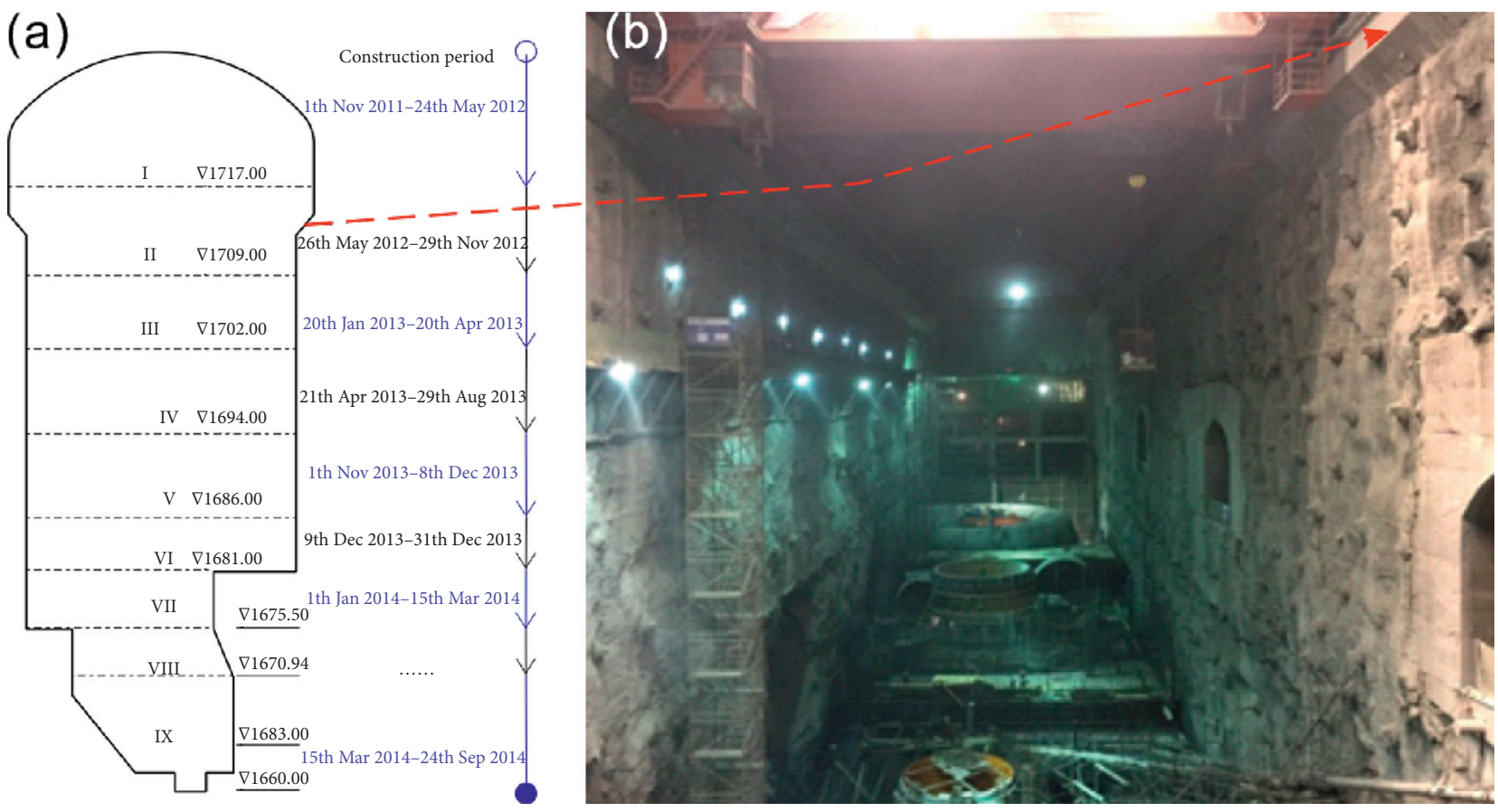

FIgURE 3: Specific stratified excavation scheme of the main powerhouse. 


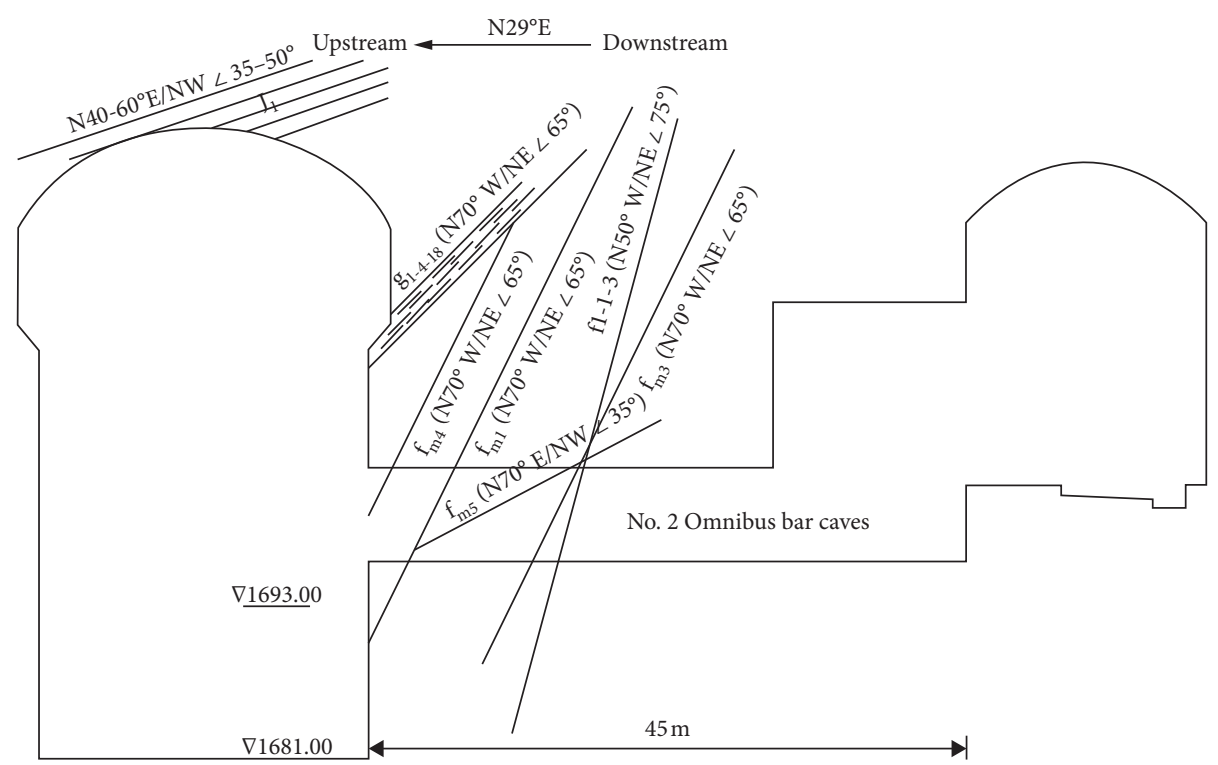

FIGURE 4: A typical geological cross-section of Houziyan hydropower station powerhouse along the center line of 2\# omnibus bar cave (stake $0+51.3 \mathrm{~m})$ (modified after Dong et al. [36]).

months, which delayed construction and resulted in substantial economic losses.

2.2. Geological Structures. The rock mass at the underground powerhouse caverns is relatively intact, and the surrounding rock masses are generally of intermediate quality. Due to detailed engineering geological explorations, no regional fractures occur in the area of the powerhouse cavern $[2,10,35]$. However, 44 small faults and 55 compression-crushed zones exist in this area; a typical geological cross-section of the underground group cavern along the center line of $2 \#$ omnibus bar cave (stake $0+51.3$ ) is shown in Figure 4. As shown in Figure 4, small faults and compression-crushed zones that exist along the surrounding rock mass between the main powerhouse and transformer chamber were the controlling factor of stability of the high sidewalls [2].

2.3. Conditions of In Situ Stress. The rock mass at the underground caverns is metamorphic limestone which has a high in situ stress. A total of 9 groups of in situ stress measurements were conducted for the underground cavern group (see Figure 5). Detailed parameters of the measurements are presented in Table 1. The measured results show that the maximum principal stresses $\sigma_{1}$ in the underground cavern group are between 21.46 and $31.43 \mathrm{MPa}$, and the direction of the maximum principal stress $\sigma_{1}$ at the dam site zone is similar to the direction of the regional tectonic principal compressive stress. The intermediate principal stresses $\sigma_{2}$ are between 12.06 and $29.8 \mathrm{MPa}$, and the minimum principal stresses $\sigma_{3}$ are between 4.83 and $22.32 \mathrm{MPa}$. The strength-stress ratio of the rock is between 2.2 and 4.0, which reveals that the underground cavern group belongs to a high field stress area. The maximum principal stress intersected with axes of the main powerhouse at a small angle of approximately $14-20^{\circ}$, which favors the stability of the main powerhouse. However, the intermediate

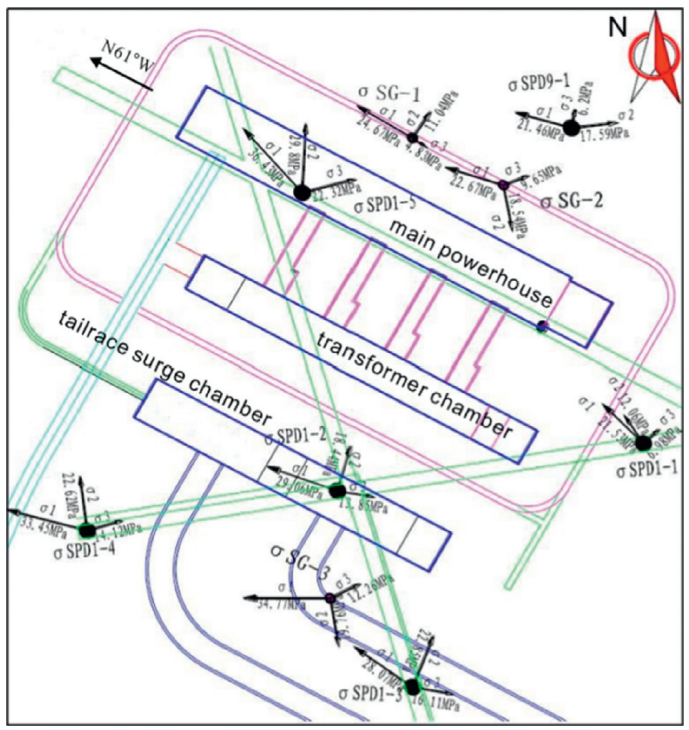

FIGURE 5: Distribution diagram of in situ stress measurement positions at the underground group cavern of Houziyan hydropower station (modified after Dong et al. [36]).

principal stress $\sigma_{2}$ intersected with axis of the main powerhouse at a large angle (see Figure 6). In particular, Figure 7(a) shows that the high stress phenomenon (i.e., irregular lamp cake cores) occurred in the in situ stress tests point, and other high stress phenomena (i.e., splitting and rib spalling) that occurred early in the excavation process in areas near the underground powerhouse are shown in Figures 7(b) and 7(c).

\section{Investigations of Excavation Damaged Zones}

3.1. Excavation Damaged Zone Terminology. The concepts of excavation-induced damage and EDZs have been studied since the early 1980s in relation to nuclear waste disposal. 
TABLE 1: The results of in situ stress measurements around the Houziyan underground powerhouse.

\begin{tabular}{|c|c|c|c|c|c|c|c|c|}
\hline No. & Points & Location & $\mathrm{H}-\mathrm{d}(\mathrm{m})$ & $\mathrm{V}-\mathrm{d}(\mathrm{m})$ & & $\sigma_{1}$ & $\sigma_{2}$ & $\sigma_{3}$ \\
\hline 1 & $\sigma_{\mathrm{SPD} 1-1}$ & $0+253 \mathrm{~m}$ in SPD1 & 253 & 390 & $\begin{array}{c}\text { Value (MPa) } \\
\alpha\left(^{\circ}\right) \\
\beta\left(^{\circ}\right)\end{array}$ & $\begin{array}{c}21.33 \\
315.69 \\
21.53 \\
\end{array}$ & $\begin{array}{l}12.06 \\
147.6 \\
68.04 \\
\end{array}$ & $\begin{array}{c}6.98 \\
47.32 \\
4.12 \\
\end{array}$ \\
\hline 2 & $\sigma_{\mathrm{SPD} 1-2}$ & $0+400 \mathrm{~m}$ in SPD1 & 400 & 560 & $\begin{array}{c}\text { Value (MPa) } \\
\alpha\left(^{\circ}\right) \\
\beta\left(^{\circ}\right) \\
\end{array}$ & $\begin{array}{c}29.06 \\
290.1 \\
42.5 \\
\end{array}$ & $\begin{array}{c}18.44 \\
15.6 \\
-4.9 \\
\end{array}$ & $\begin{array}{c}13.85 \\
100.3 \\
47.1 \\
\end{array}$ \\
\hline 3 & $\sigma_{\mathrm{SPD} 1-3}$ & $0+106 \mathrm{~m}$ in the lower adit of SPD1 & 400 & 570 & $\begin{array}{c}\text { Value }(\mathrm{MPa}) \\
\alpha\left(^{\circ}\right) \\
\beta\left({ }^{\circ}\right) \\
\end{array}$ & $\begin{array}{c}28.07 \\
305.5 \\
47.5 \\
\end{array}$ & $\begin{array}{c}22.85 \\
21.2 \\
-12.8 \\
\end{array}$ & $\begin{array}{c}16.11 \\
100.4 \\
39.7 \\
\end{array}$ \\
\hline 4 & $\sigma_{\mathrm{SPD} 1-4}$ & $0+525 \mathrm{~m}$ in SPD1 & 525 & 780 & $\begin{array}{c}\text { Value (MPa) } \\
\alpha\left(^{\circ}\right) \\
\beta\left(^{\circ}\right) \\
\end{array}$ & $\begin{array}{c}33.45 \\
285.3 \\
54.3 \\
\end{array}$ & $\begin{array}{r}22.62 \\
352.9 \\
-15.3 \\
\end{array}$ & $\begin{array}{c}14.12 \\
73.3 \\
31.4 \\
\end{array}$ \\
\hline 5 & $\sigma_{\mathrm{SPD} 1-5}$ & $0+236 \mathrm{~m}$ in the fourth adit of SPD1 & 385 & 576 & $\begin{array}{c}\text { Value (MPa) } \\
\alpha\left(^{\circ}\right) \\
\beta\left(^{\circ}\right)\end{array}$ & $\begin{array}{c}36.43 \\
319.3 \\
44.5 \\
\end{array}$ & $\begin{array}{c}29.8 \\
3.3 \\
-36.2 \\
\end{array}$ & $\begin{array}{c}22.32 \\
74.7 \\
23.6 \\
\end{array}$ \\
\hline 6 & $\sigma_{\mathrm{SPD} 9-1}$ & $0+250 \mathrm{~m}$ in SPD9 & 250 & 440 & $\begin{array}{c}\text { Value (MPa) } \\
\alpha\left(^{\circ}\right) \\
\beta\left(^{\circ}\right)\end{array}$ & $\begin{array}{c}21.46 \\
286.2 \\
47.1 \\
\end{array}$ & $\begin{array}{c}17.59 \\
96.7 \\
42.5 \\
\end{array}$ & $\begin{array}{c}6.2 \\
11.1 \\
-4.8 \\
\end{array}$ \\
\hline 7 & $\sigma_{\mathrm{SG}-1}$ & $0+41 \mathrm{~m}$ in the 2 nd-layer drainage gallery & 330 & 500 & $\begin{array}{c}\text { Value (MPa) } \\
\alpha\left(^{\circ}\right) \\
\beta\left(^{\circ}\right)\end{array}$ & $\begin{array}{c}24.67 \\
301.3 \\
67.6 \\
\end{array}$ & $\begin{array}{c}11.04 \\
33.5 \\
0.9 \\
\end{array}$ & $\begin{array}{c}4.83 \\
123.9 \\
22.4 \\
\end{array}$ \\
\hline 8 & $\sigma_{\mathrm{SG}-2}$ & $0+90 \mathrm{~m}$ in the 2 nd-layer drainage gallery & 280 & 480 & $\begin{array}{c}\text { Value }(\mathrm{MPa}) \\
\alpha\left(^{\circ}\right) \\
\beta\left(^{\circ}\right)\end{array}$ & $\begin{array}{c}22.67 \\
288.0 \\
54.2 \\
\end{array}$ & $\begin{array}{c}18.54 \\
169.4 \\
19.0 \\
\end{array}$ & $\begin{array}{l}9.65 \\
68.4 \\
29.0 \\
\end{array}$ \\
\hline 9 & $\sigma_{\mathrm{SG}-3}$ & $0+59 \mathrm{~m}$ in the upstream sidewall of No. 2 tailrace tunnel & 430 & 580 & $\begin{array}{c}\text { Value }(\mathrm{MPa}) \\
\alpha\left(^{\circ}\right) \\
\beta\left(^{\circ}\right)\end{array}$ & $\begin{array}{c}34.77 \\
270.0 \\
34.5 \\
\end{array}$ & $\begin{array}{c}19.76 \\
170.5 \\
13.5 \\
\end{array}$ & $\begin{array}{c}12.26 \\
62.5 \\
52.2\end{array}$ \\
\hline
\end{tabular}

Note: $\mathrm{H}-\mathrm{d}$ is the horizontal depth of the measured point, while $\mathrm{V}-\mathrm{d}$ is the vertical depth of the measured point. $\alpha$ is the dip direction of the principal stress and $\beta$ is the dip angle of the principal stress.

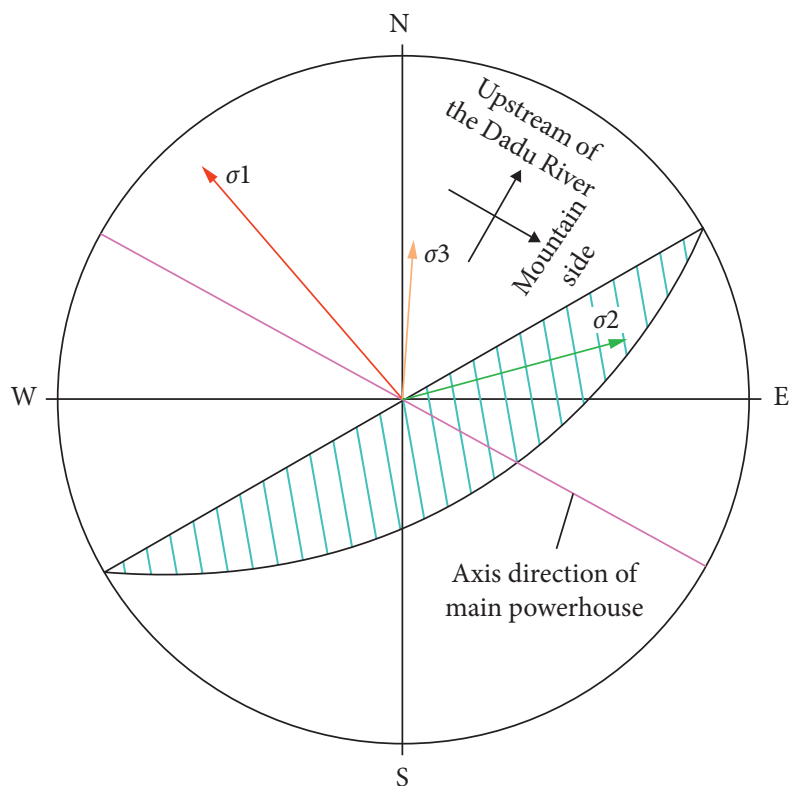

FIGURE 6: Spatial relationship between the axis principle stresses and main powerhouse in Houziyan project.

The terminology related to damage zones has changed from the early investigations, due to the improved understanding of evolution process and mechanisms of the damaged zones
[35]. Siren et al. [27] provided a brief and up-to-date description of these zones. Xu et al. [34, 37] provided a review of these zones and proposed the terminology of Excavation Highly Damaged Zone (EHDZ), Excavation Slightly Damaged Zone (ESDZ), and Undamaged Zone (UDZ), and various zones therein are depicted in Figure 8. However, the Undamaged Zone (UDZ) is typically of minimal interest for group of underground caverns. In contrast, Excavation Influence Zone (EIZ) proposed by Siren et al. [27] is bettersuited to describing UDZ that was mentioned above. Consequently, we divided the EDZs into HDZ, SDZ, and EIZ in this study.

3.2. Detection Method. Extensive research has been conducted on EDZs with field observations and measurements, theoretical calculations, and numerical simulations [35]. As mentioned in the "Introduction" of this paper, field detection methods commonly include multiple position extensometers, acoustic emission (AE) monitoring, microseismic (MS) monitoring, and borehole television (TV). Among them, MS data have been used to identify early warning of abnormal displacements in the recent ten years, in an attempt to provide more reasonable and practical guidelines for supporting measures. Nevertheless, most of the previous research works only use the MS technique as a qualitative analytical method for the deformation forecasting. Acoustic 

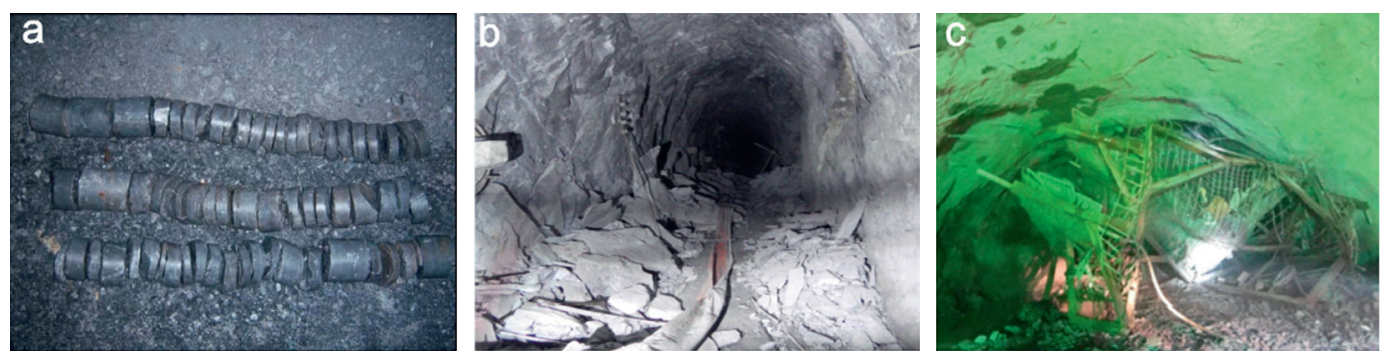

FIGURE 7: The high stress phenomena in the underground powerhouse: (a) the irregular lamps cake core, (b) rock mass splitting and spalling occurring at the 2nd-layer drainage gallery, and (c) roof collapse induced by rock burst in No. 2 tailrace tunnel in the underground powerhouse.

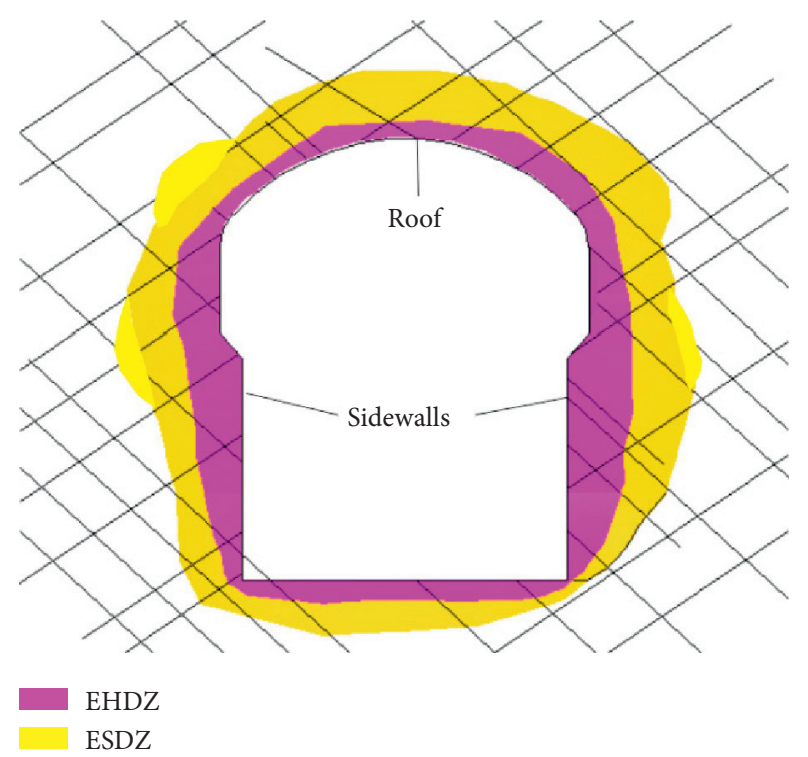

Figure 8: The excavation damage zones proposed by $\mathrm{Xu}$ et al. $[34,37]$. Note that UDZ is not illustrated in the figure.

velocity testing has been widely used for the assessment of EDZs in underground caverns and dam foundations [38] after excavation, due to its high accuracy and efficacy. In fact, the detecting results of EDZs with acoustic velocity method have always been the necessary material for the acceptance of the project owner in hydropower industry. Meanwhile, other methods such as borehole television and permeability test should be employed at some key positions.

In this study, the single-hole acoustic wave monitoring method which was based on the theory of elastic wave propagation in solid media was applied. A simple illustration of the principle of the single-hole detection technique is shown in Figure 9. The source and receiving probes were inserted into the boreholes. This triggered the source probes to generate waves, which were refracted several times and received by probes S1 and S2. The waves were finally converted into electrical signals and stored in the host computer. Then data from all monitored points along each borehole were processed to obtain the depth and wave velocity curves. The formulation of the wave velocity at each monitored point can be expressed as follows:

$$
V_{p}=\frac{L}{\left(t_{1}-t_{2}\right)},
$$

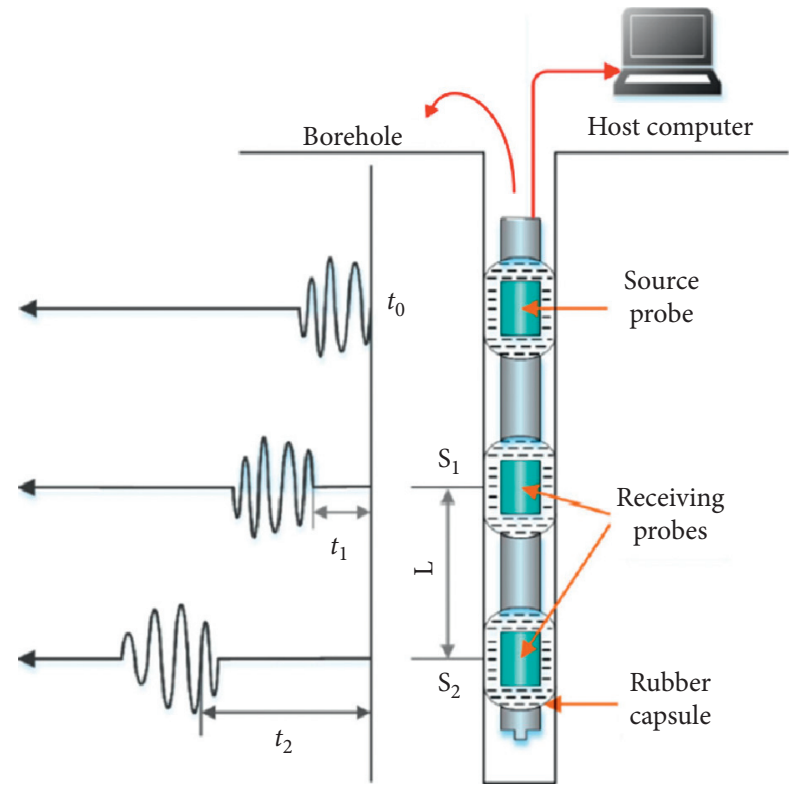

FIgURE 9: Principle of acoustic velocity testing system, modified after Tao et al. [28].

where $t_{1}$ and $t_{2}$ represent the initial times when receiving probes S1 and S2 start receiving signals, respectively, and $L$ represents the distance between the two receiving probes.

Generally, the velocity of acoustic wave decreased with the development of micro- and macrofractures. That is, the wave velocity decreased with increasing acoustic impedance and fracture development, and it increased with increasing rock mass stress and density [5]. A total of 30 test sites distributed in five sections of main powerhouse in Houziyan hydropower project were designed as the measuring points during the construction process, but only particle data were collected and analyzed in this paper. The operating principle and specific section of the testing boreholes are shown in Figures 10 and 11, respectively. It can be clearly seen that EDZs were detected in 5 testing sections, and each section was allocated seven testing boreholes around surrounding rock mass, with the designed boreholes distributed in elevation of $1724.00 \mathrm{~m}, 1718.00 \mathrm{~m}, 1711.00 \mathrm{~m}, 1704.00 \mathrm{~m}$, $1697.00 \mathrm{~m}, 1690.00 \mathrm{~m}$, and $1683.00 \mathrm{~m}$, respectively. The testing boreholes were drilled after each excavation step, with a depth of $20 \mathrm{~m}$ and diameter of $76 \mathrm{~mm}$. Most of the designed boreholes are arranged in the surrounding rock 


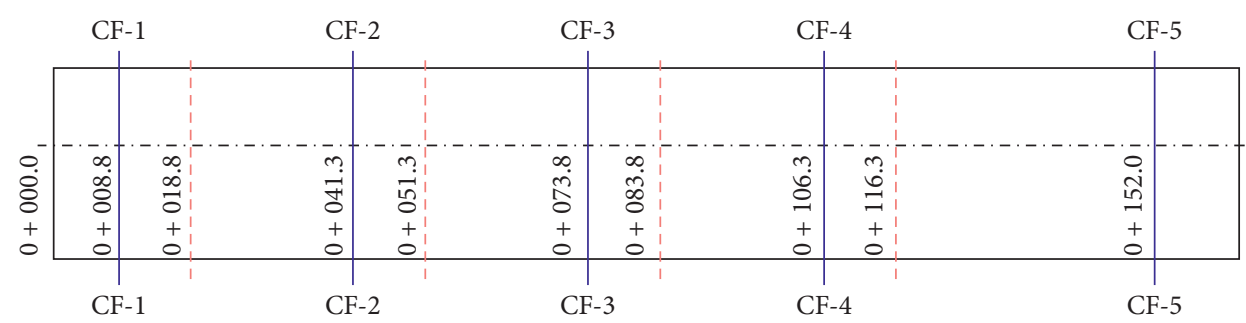

FIGURE 10: The layout of a designed section of acoustic velocity test in a special elevation in the main powerhouse of Houziyan project.

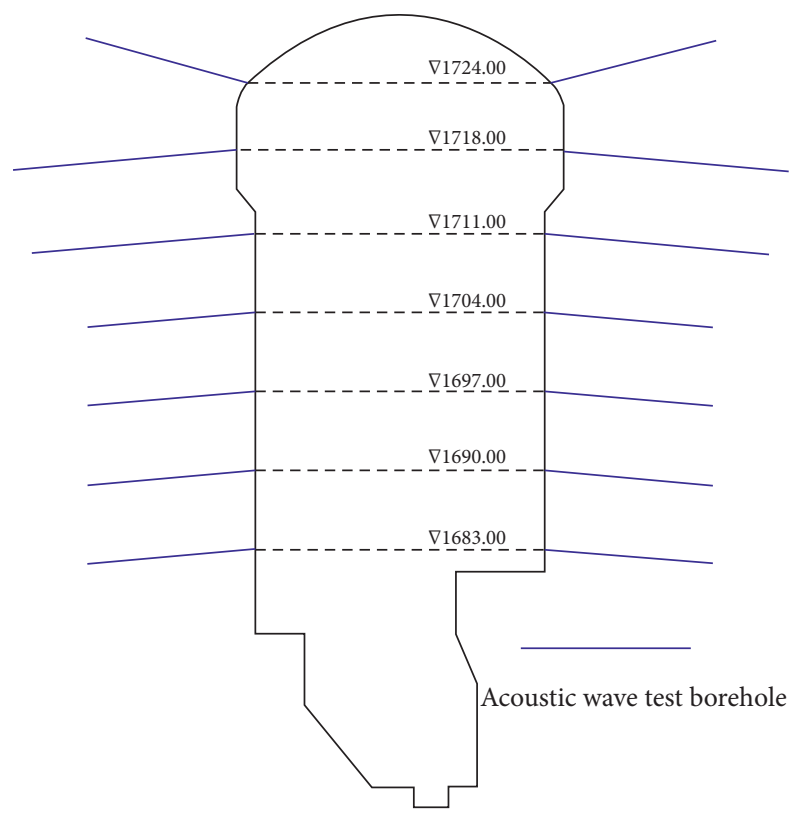

Figure 11: A typical layout of acoustic velocity test boreholes around a section of the main powerhouse of Houziyan project.

mass of the high sidewalls, so the stability of surrounding rock mass of the high sidewalls is the crucial issue.

3.3. Assessment Method of EDZs. The estimation of damage extent and intensity and the study of mechanical characteristics of surrounding rocks both have significant effects on safety evaluation and optimization of supporting parameters in rock engineering. For instance, the length and layout of bolts are directly determined by the range of EDZs. Consequently, quantitative assessment is demanded to provide practical guidelines for supporting measures. In this study, acoustic wave curves obtained in the main powerhouse were classified into four types: type I, type II, type III, and type IV, as shown in Figure 12. Qualitative assessment could be put into effect according to classification of the wave curves.

For type I, the curve includes three parts: a "lower velocity with slow rise" section near surfaces of the excavation site zone where the surrounding rock mass is heavily damaged (HDZ); a "rise with fluctuation" section where parallel fresh cracks are initiated by stress redistribution and where the velocity is lower near cracks (SDZ); and a "high wave velocity with minor fluctuations" section in the deeper zone where the surrounding rock mass is distributed but not damaged (EIZ). For type II, the curve could also be divided into three parts; it was mainly found during stress regulation after excavation. However, the velocity did not rise in the HDZ, with a lower velocity near the boundaries of the excavation site. For type III, the curve was divided into two parts, and it differed from type I and type II in that "rise with fluctuation wave velocity" sections were not present. The curve of type III mainly occurred in the high stress concentration-induced failure area. For this type, the surrounding rock mass was heavily damaged in the area along the borders of the excavation site but was not as affected in deeper areas. For type IV, which was mainly found during the lining stage after excavation when the EDZs were emerging and expanding, the acoustic wave curve could be divided into two parts: a part of "rise of wave velocity with fluctuation" and a part of "high wave velocity with minor fluctuations", respectively.

Figure 13 presents two typical test results measured in section $0+008.8 \mathrm{~m}$ in the main powerhouse of Houziyan project. It can be easily assessed by identifying the categories of the wave velocity curves. As shown in Figure 13(a), the wave velocity curves were firstly obtained on Nov 18, 2012, as the velocity of $0-6 \mathrm{~m}$ rose with fluctuation; then the wave velocity reached up to $6000-6300 \mathrm{~m} / \mathrm{s}$ along the entire test borehole, the category of the curve was type IV, and the depth of HDZ/SDZ was easily confirmed to be approximately $6 \mathrm{~m}$ according to Figure 12(a). Obviously, the acoustic velocity curves evolved from type IV to type I to type II in Figure 12(a) and evolved from type IV to type I to type III in Figure 12(b). The EDZs were enlarged because of microcrack initiation, propagation, and coalescence due to unloading and deformation. Then, with an increase in excavation steps, cracks and EDZs gradually expanded into deeper ground layers because of excavation disturbances and increasing sidewall heights.

Li et al. [5] have illustrated that wave velocity of the HDZ in the underground caverns of Jinping I project was relatively low (below $3500 \mathrm{~m} / \mathrm{s}$ ); wave velocity fluctuated between 4000 and $5500 \mathrm{~m} / \mathrm{s}$ in SDZ and reached up to values ranging from $5500 \mathrm{~m} / \mathrm{s}$ to $6000 \mathrm{~m} / \mathrm{s}$ in EIZ. Nevertheless, assessment of EDZs using only the values of wave velocity is not reasonable, because wave velocity of the rock mass is influenced by many factors such as in situ stress, water, and joint development. Therefore, index of " $\mathrm{D}$ " was proposed by $\mathrm{Xu}$ et al. $[34,37]$, which could be understood as an index of the damage degree of the rock mass and used to assess the depths of EDZs quantitatively. The value of D was expressed as follows: 


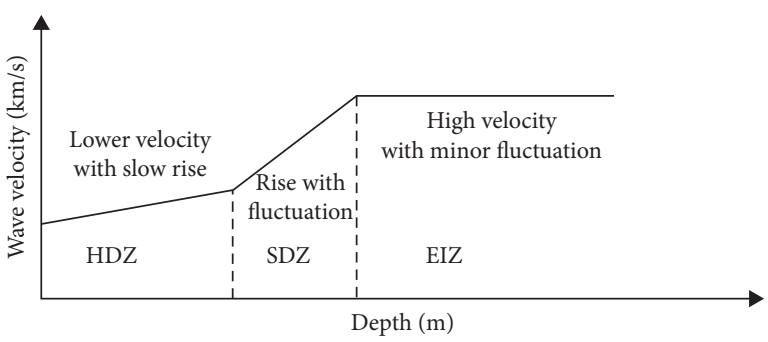

(a)

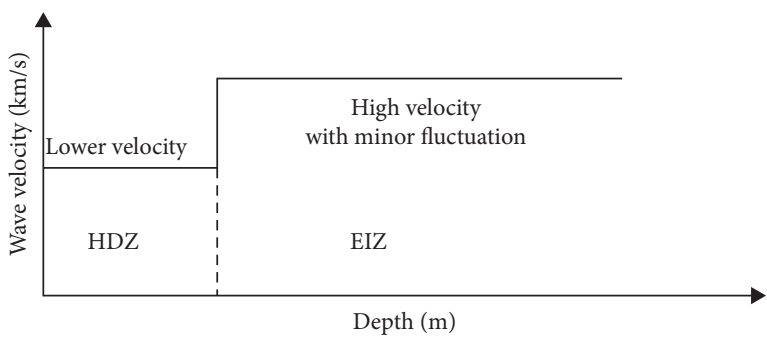

(c)

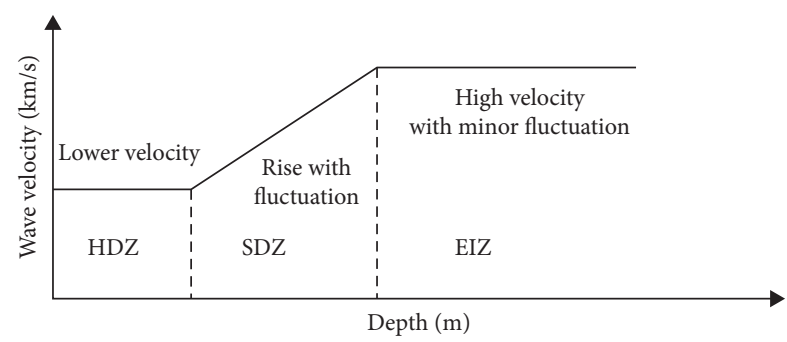

(b)

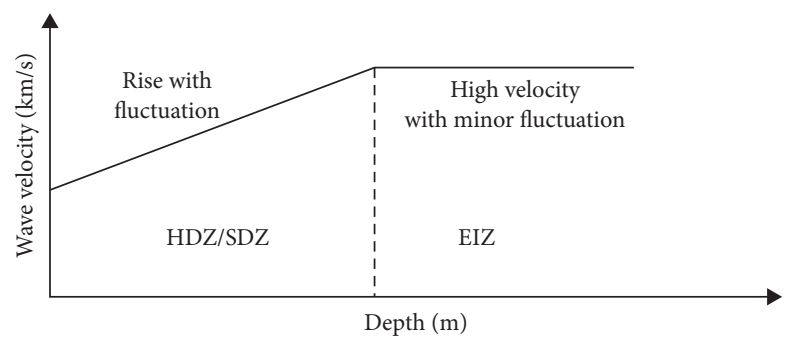

(d)

FIGURE 12: Four types of acoustic wave curves of the surrounding rock mass in the underground powerhouse of the Houziyan hydropower project: (a) type I (b) type II, (c) type III, and (d) type IV.

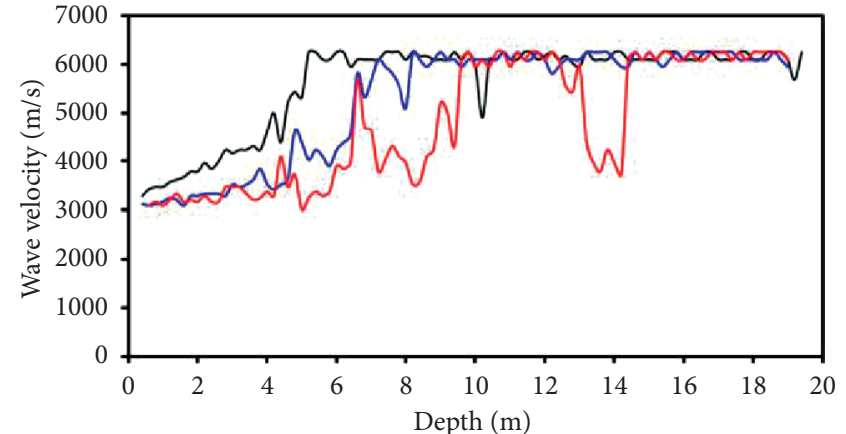

- Nov 18,2012
- Jun 16,2013
- Sep 14, 2013

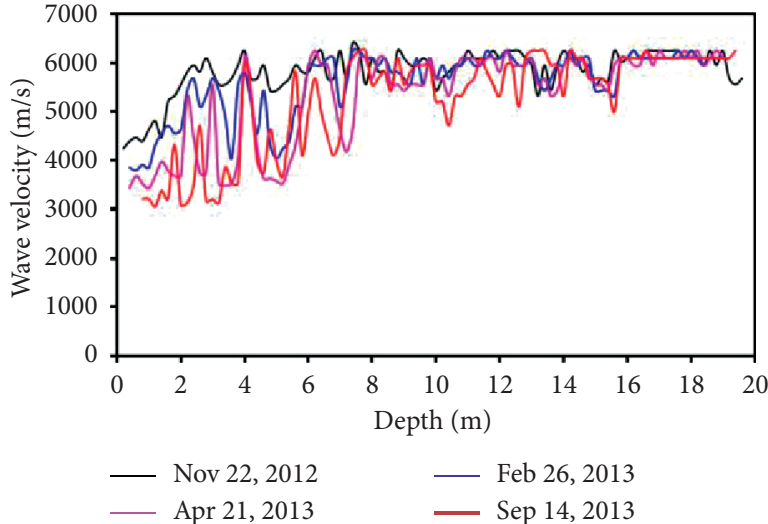

(b)

Figure 13: Typical test results of acoustic wave curves measured in the upstream sidewall of the main powerhouse during excavation (a) in section of $0+041.3 \mathrm{~m}$ (elevation of $1718.00 \mathrm{~m}$ ) and (b) in section of $0+008.8 \mathrm{~m}$ (elevation of $1718.00 \mathrm{~m}$ ).

$$
D=1-\frac{\bar{V}_{p}^{2}}{V_{p}^{2}},
$$

where $\bar{V}_{p}$ represents the P-wave velocity of the rock mass in extent of EDZs, and $V_{p}$ is the P-wave velocity of the undistributed rock mass, not the P-wave velocity of the fresh rock. According to $\mathrm{Xu}$ et al. [34], the rock mass was heavily damaged (HDZ) when the value of $\mathrm{D}$ was greater than 0.6 , slightly damaged (SDZ) when D ranged from 0.6 to 0.2 , and only distributed but not damaged when the value of $\mathrm{D}$ was smaller than 0.2. A typical wave curve and borehole images obtained in section of $0+008.8 \mathrm{~m}$ and elevation of $1711.00 \mathrm{~m}$ in the downstream sidewall are shown in Figure 14. The rock mass was heavily damaged with densely distributed extrusion cracks accompanied by shear cracks observed in the testing borehole (see Figure 14(b)). Quantitative assessment results by damage factor $\mathrm{D}$ show that the depth of $\mathrm{HDZ}$ in the measured area was $5.4 \mathrm{~m}$; next to the HDZ, zones of $5.4 \mathrm{~m}$ to $14.6 \mathrm{~m}$ were SDZs. Consequently, the densities and magnitudes of induced fractures and cracks in EDZs should decrease from the boundaries of the excavation site to a farfield undisturbed state. In contrast, the wave velocity increased gradually.

3.4. Assessment Results of EDZs. A total of 19 testing boreholes were implemented, and 153 corresponding curves were obtained during excavation in the main powerhouse in Houziyan project. Most of these data were gathered, and qualitative and quantitative analysis were promoted. The depth values of EDZs of the main section are listed in 

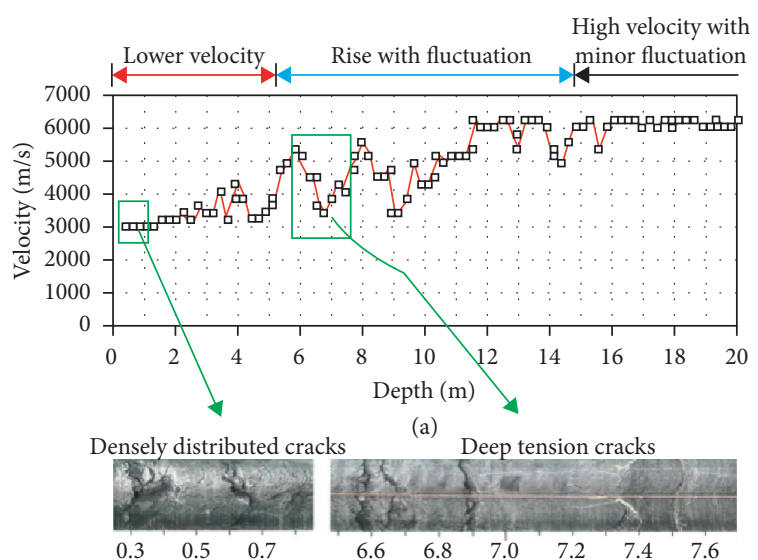

(b)

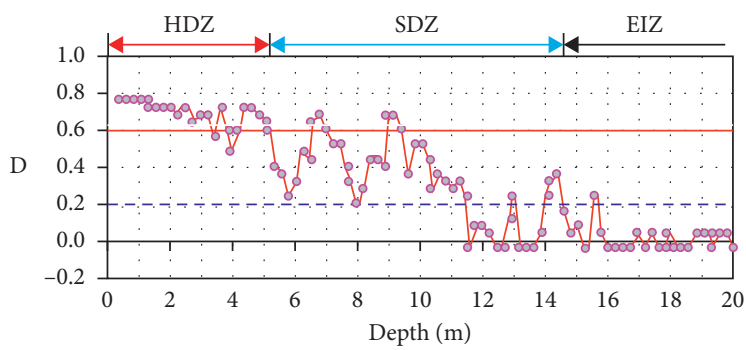

(c)

Figure 14: Excavation damaged zones (EDZs) along the depth of the rock mass surrounding the Houziyan main powerhouse: (a) a typical account of the acoustic wave velocity in the surrounding rock mass, (b) a typical account of a borehole TV of fractures in the surrounding rock mass, and (c) corresponding D curves and classification of EDZs in the testing borehole.

Table 2, and the typical distribution of EDZs in different sections is illustrated in Figure 15. It was found that depth of $\mathrm{HDZ}$ in the downstream sidewalls ranged from $2.1 \mathrm{~m}$ to $12.4 \mathrm{~m}$, and depth of HDZ in the upstream sidewalls ranged from $1.6 \mathrm{~m}$ to $8.2 \mathrm{~m}$. In addition, greater depth of HDZ was found in elevation of $1718.00 \mathrm{~m}$ and $1711.00 \mathrm{~m}$, which indicated that surrounding rock mass was highly damaged. It can also be seen from Figure 15 that the depth of HDZ in the downstream sidewall is larger and asymmetric. As a result, deformation was distributed similarly to the depth distribution of EDZs.

\section{Discussion}

EDZs distribution characteristics around the large-scale hydropower underground caverns correlated with many factors such as in situ stress, mechanical parameters of the rock mass, rock mass quality, back-pressure by rock supports, structural planes, the control of blasting vibrations, the influence of adjacent excavations, and the excavation process. Among these factors, the in situ stress and the length of rock bolts directly related to the back-pressure are the main two factors [11]. As seen in Figure 16, the situ stresses in the section plane of the main powerhouse are $\sigma_{1}$ and $\sigma_{2}$, and the values are 31.9 and 27.01 Mpa, respectively. The intermediate principal stress $\sigma_{2}$ was relatively large, and it was subvertical to the axis of the main powerhouse. As a result, the radial stress, which was approximately parallel to the intermediate principle stress, was markedly increased, the radial stress quickly decreased to near zero, and the rock mass rebounded and deformed toward the excavation surface, thus in turn leading to the concentration of tension stress at the tips of preexisting microcracks. Subsequently, extent of the EDZs at the upstream and downstream high sidewalls could be much larger. In addition, depth of EDZs correlated with the geological structures such as small faults and compression-crushed zones introduced in Section 2.2, which is consistent with the findings by $\mathrm{Xu}$ et al. [2].

EDZs were also influenced by excavation and rock mass quality. A typical curve of EDZs evolution process was shown in Figure 17, indicating the extent of EDZs versus time at various excavation stages, with EDZs expanding fast in excavation stage of III and IV due to the high sidewall formation and the accompanying stress redistribution. In contrast, extent of EDZs was not enlarged during the excavation stop period. It is the positive effect of dynamic reinforcement supporting measures carried out, such as grouting six rows of additional anchor cables, which had a length of $20 \mathrm{~m}$ and were arranged in sidewalls on elevation $1720.30 \mathrm{~m}, 1710 \mathrm{~m}, 1706 \mathrm{~m}, 1702 \mathrm{~m}, 1698 \mathrm{~m}$, and $1692 \mathrm{~m}$, respectively. These dynamic reinforcement supporting measures make the rock mass quality higher and restrain crack development. Differently, the asymmetric distribution of EDZs shown in Figure 15 can be explained as the influence of small faults and compression-crushed zones distributed mainly in the downstream site.

In respect of assessment reliability, we assessed the depths of EDZs using the comprehensive method, which 
TABle 2: Depth of EDZs around the main powerhouse in Houziyan project.

\begin{tabular}{|c|c|c|c|c|c|}
\hline \multicolumn{2}{|c|}{ Position of testing boreholes } & \multicolumn{2}{|c|}{ Upstream } & \multicolumn{2}{|c|}{ Downstream } \\
\hline Elevation $(\mathrm{m})$ & Section $(\mathrm{m})$ & Depth of HDZ (m) & Depth of SDZ (m) & Depth of HDZ (m) & Depth of SDZ (m) \\
\hline 1718 & $0+008.8$ & 5.8 & 10.5 & 12.4 & 19.8 \\
\hline 1718 & $0+041.3$ & 4.4 & 6.2 & 11.5 & 16 \\
\hline 1718 & $0+73.8$ & 3.8 & 9.4 & 6 & 17.7 \\
\hline 1718 & $0+106.3$ & 3.6 & 19.8 & 3.8 & 11.6 \\
\hline 1718 & $0+152.0$ & 8.2 & 9.6 & 2.1 & 4 \\
\hline 1711 & $0+008.8$ & 2.8 & 8.4 & 10 & 17 \\
\hline 1711 & $0+041.3$ & 5.2 & 10 & 12 & 14 \\
\hline 1711 & $0+73.8$ & 3.6 & 11 & 10 & 17.2 \\
\hline 1711 & $0+106.3$ & 6.9 & 11.8 & 10.7 & 11.2 \\
\hline 1711 & $0+152.0$ & 4.2 & 6.2 & 4.2 & 8.8 \\
\hline 1704 & $0+008.8$ & 3.2 & 6 & 10.3 & 14.8 \\
\hline 1704 & $0+041.3$ & 1.6 & 14.5 & 12 & 13.7 \\
\hline 1704 & $0+73.8$ & 3.2 & 13.2 & 4.2 & 12.8 \\
\hline 1704 & $0+106.3$ & 5.4 & 7.6 & 7.6 & 14 \\
\hline 1704 & $0+152.0$ & 3.2 & 8 & 2.4 & 9 \\
\hline 1697 & $0+008.8$ & 2.5 & 10.1 & 5.4 & 9 \\
\hline 1697 & $0+041.3$ & 5.8 & 18 & 7.3 & 10.2 \\
\hline 1697 & $0+73.8$ & 2 & 20.6 & 7.9 & 13.6 \\
\hline 1697 & $0+106.3$ & 2 & 12.2 & 2.8 & 6.4 \\
\hline
\end{tabular}

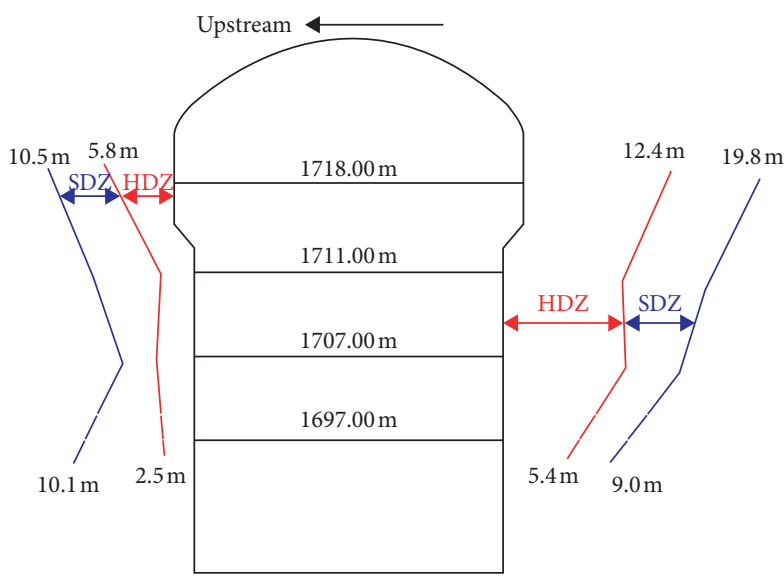

(a)

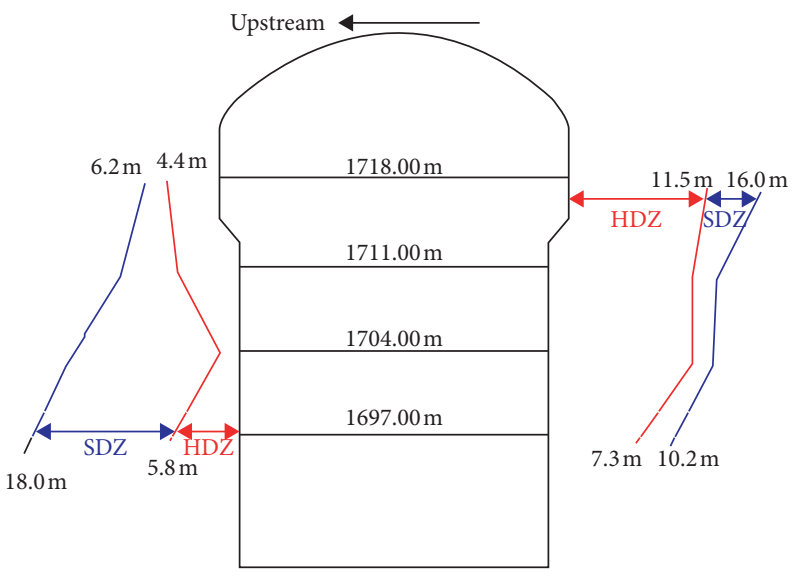

(b)

FIGURE 15: Depths of EDZs distributed in typical measured sections of Houziyan hydropower project: (a) section $0+008.8 \mathrm{~m}$ and (b) section of $0+041.3 \mathrm{~m}$.

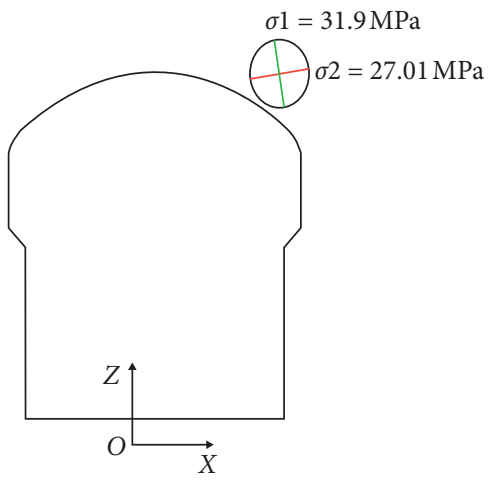

FIGURE 16: Stress distribution before excavation in section of the main powerhouse in Houziyan project. 


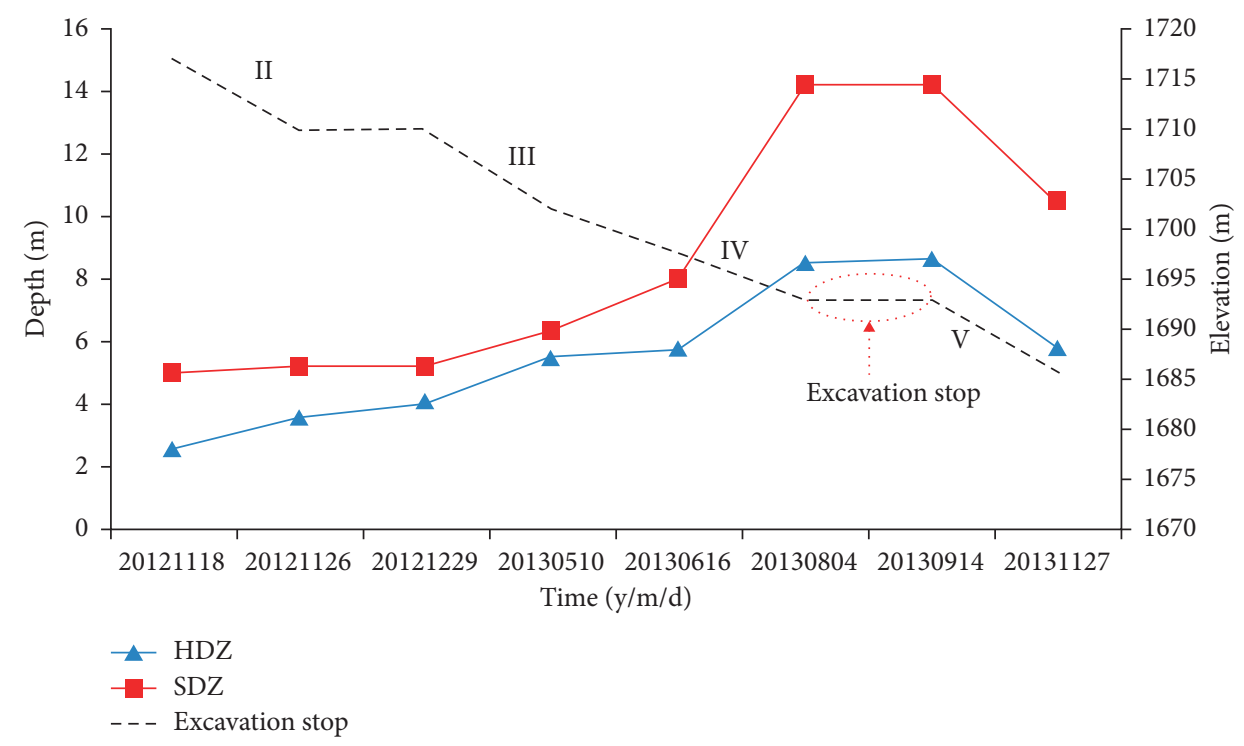

FIgUre 17: A typical process of EDZs evolution in section of $0+008.8 \mathrm{~m}$ in the main powerhouse of Houziyan project.

incorporates the qualitative and quantitative methods. The former method was based on discrimination of categories of the acoustic wave velocity (type I, type II, type III, and type IV), and the latter was based on quantitative calculation of an index named $\mathrm{D}$, which represents the damage degree of rock mass. The designed length of rock bolts was $6 \mathrm{~m}$ and $8 \mathrm{~m}$; obviously, it was shorter than depth of EDZs (mainly concerning the depth of HDZ) in most areas of the downstream sidewalls and areas of the upstream sidewalls above elevation $1711.0 \mathrm{~m}$. Large deformation and failure phenomena such as shotcrete bulking and cracking, which occurred frequently in both upstream and downstream sidewalls, demonstrated that the assessment results were reliable and reasonable. Nevertheless, recognition of categories of wave velocity curves involves subjectivity, and evolution process cannot be considered before the wave velocity testing; herein, the latter is a common disadvantage with other methods such as microseismic (MS) monitoring and the borehole television.

\section{Conclusions}

In the present study, project background of the underground main powerhouse of Houziyan hydropower was introduced and analyzed. To obtain the extent of EDZs, a total of 38 testing boreholes were made, and 153 corresponding wave velocity curves were gathered. The depths of EDZs were assessed by the proposed quantitative method, and then formation mechanism and evolution of EDZs were discussed. The following conclusions can be drawn:

Firstly, according to the in situ testing results, failure phenomena occurred in the testing boreholes and were exposed after excavation such as irregular lamps cake core, splitting, and spalling, showing that geostresses in the Houziyan underground powerhouse belong to the high in situ stress. The relatively large intermediate principal stresses $\sigma_{2}$ were subvertical to the axis of the main powerhouse, which directly caused the concentration of tension stress and intensive damage of the surrounding rock mass.

Secondly, acoustic wave velocity curves obtained from the field test in Houziyan project were classified into four categories: type I, type II, type III, and type IV. According to the curves categories, EDZs were divided into HDZ, SDZ, and EIZ. A quantitative index (D) representing the damage degree was used to assess the depth of EDZs, combined with a qualitative assessment based on categories recognition of the wave velocity curves.

Finally, according to the EDZs assessment results, depth of EDZs was distributed asymmetrically. The depths of HDZ in the upstream sidewall ranged from $1.6 \mathrm{~m}$ to $8.2 \mathrm{~m}$, with an average of $4.1 \mathrm{~m}$, which is smaller than the length of rock bolts. The depth of HDZ in the downstream sidewall was significantly greater than that of the upstream sidewall, ranging from $2.1 \mathrm{~m}$ to $12.4 \mathrm{~m}$, with an average of $7.5 \mathrm{~m}$. The corresponding average depth of SDZ is $11.2 \mathrm{~m}$ in the upstream sidewall and $12.7 \mathrm{~m}$ in the downstream sidewall.

\section{Data Availability}

The data used to support the findings of this study are included within the article.

\section{Conflicts of Interest}

The authors declare that there are no conflicts of interest regarding the publication of this paper.

\section{Acknowledgments}

This work was supported by the National Natural Science Foundation of China (51874160), Liaoning Higher Education Innovation Team Support Program (LT2018008), and Liaoning Higher Education Innovative Talent Support Program Project (LR2016039). This study was also sponsored by the Talent Development Program of Kunming 
University of Science and Technology (No. KKSY201504022). The authors thank Prof. Xu Guangli for his contribution to the data gathering due to his remarkable leadership.

\section{References}

[1] Q. Fan and Y. Wang, "A case study of rock mass engineering of underground powerhouse at Xiluodu hydropower station," Chinese Rock Mechanics and Engineering, vol. 30, pp. 29862993, 2011.

[2] N. W. Xu, T. B. Li, F. Dai, B. Li, Y. G. Zhu, and D. S. Yang, "Microseismic monitoring and stability evaluation for the large scale underground caverns at the houziyan hydropower station in southwest China," Engineering Geology, vol. 188, no. 4, pp. 48-67, 2015.

[3] F. Dai, B. Li, N. Xu, Y. Fan, and C. Zhang, "Deformation forecasting and stability analysis of large-scale underground powerhouse caverns from microseismic monitoring," International Journal of Rock Mechanics and Mining Sciences, vol. 86, pp. 269-281, 2016.

[4] Y. Shen, G. Xu, and J. Yi, “A systematic engineering geological evaluation of diabase dikes exposed at the underground caverns of dagangshan hydropower station, Southwest China," Environmental Earth Sciences, vol. 76, no. 14, p. 481, 2017.

[5] H.-B. Li, M.-C. Liu, W.-B. Xing, S. Shao, and J.-W. Zhou, "Failure mechanisms and evolution assessment of the excavation damaged zones in a large-scale and deeply buried underground powerhouse," Rock Mechanics and Rock Engineering, vol. 50, no. 7, pp. 1883-1900, 2017.

[6] P.-W. Xiao, T.-B. Li, N.-W. Xu, Z. Zhou, and X.-H. Liu, "Microseismic monitoring and deformation early warning of the underground caverns of lianghekou hydropower station, Southwest China," Arabian Journal of Geosciences, vol. 12, no. 16, pp. 1-18, 2019.

[7] A. Li, Y. Liu, F. Dai, K. Liu, and M. Wei, "Continuum analysis of the structurally controlled displacements for large-scale underground caverns in bedded rock masses," Tunnelling and Underground Space Technology, vol. 97, Article ID 103288, 2020.

[8] Q. Jiang, G. Su, X.-T. Feng, G. Chen, M.-Z. Zhang, and C. Liu, "Excavation optimization and stability analysis for large underground caverns under high geostress: a case study of the chinese laxiwa project," Rock Mechanics and Rock Engineering, vol. 52, no. 3, pp. 895-915, 2019.

[9] G. Liu, X. Feng, Q. Jiang et al., "Failure characteristics, laws and mechanisms of rock spalling in excavation of large-scale underground powerhouse caverns in baihetan," Chinese Rock Mechanics and Engineering, vol. 35, no. 5, pp. 865-878, 2016.

[10] Q. Fan, Y. Liu, and Z. Yi, "Key technology of tailrace system at Xiangjiaba right-bank underground powerhouse," Chinese Rock Mechanics and Engineering, vol. 31, no. 12, pp. 23772388, 2012.

[11] P. Yan, W.-B. Lu, M. Chen, Y.-G. Hu, C.-B. Zhou, and $\mathrm{X} . \mathrm{X}$. Wu, "Contributions of in-situ stress transient redistribution to blasting excavation damage zone of deep tunnels," Rock Mechanics and Rock Engineering, vol. 48, no. 2, pp. 715-726, 2015.

[12] Z. Li, G. Xu, J. Dong, H. Chu, J. Wang, and C. Chen, "Geomechanics mechanism and characteristics of surrounding rock mass failure for underground powerhouse under high geostress," Journal of Central University (Science and Technology), vol. 48, no. 6, pp. 1568-1576, 2017.
[13] Z. Qin, H. Fu, and X. Chen, "A study on altered granite mesodamage mechanisms due to water invasion-water loss cycles," Environmental Earth Sciences, vol. 78, no. 14, p. 428, 2019.

[14] J. Wang, S.-C. Li, L.-P. Li, P. Lin, Z.-H. Xu, and C.-L. Gao, "Attribute recognition model for risk assessment of water inrush," Bulletin of Engineering Geology and the Environment, vol. 78, no. 2, pp. 1057-1071, 2019.

[15] N. Wu, Z. Z. Liang, J. R. Zhou, and Y. Z. Zhang, "Energy evolution characteristics of coal specimens with preformed holes under uniaxial compression," Geomechanics and Engineering, vol. 20, no. 1, pp. 55-66, 2020.

[16] W. Liu, W. Yuan, Y. Yan, and X. Wang, "Analysis of acoustic emission characteristics and damage constitutive model of coal-rock combined body based on particle flow code," Symmetry, vol. 11, no. 8, p. 1040, 2019.

[17] F. Ren, C. Zhu, and M. He, "Moment tensor analysis of acoustic emissions for cracking mechanisms during schist strain burst," Rock Mechanics and Rock Engineering, vol. 53, no. 1, pp. 153-170, 2020.

[18] W. Liu, J. Liu, and C. Zhu, "Multi-scale effect of acoustic emission characteristics of 3D rock damage," Arabian Journal of Geosciences, vol. 12, no. 22, p. 668, 2019.

[19] Q. L. Zou, H. Liu, Z. H. Cheng, T. C. Zhang, and B. Q. Lin, "Effect of slot inclination angle and borehole-slot ratio on mechanical property of pre-cracked coal: implications for ECBM recovery using hydraulic slotting," Natural Resources Research, vol. 29, no. 3, pp. 1705-1729, 2019.

[20] Q. Zou, H. Liu, Y. Zhang, Q. Li, J. Fu, and Q. Hu, "Rationality evaluation of production deployment of outburst-prone coal mines: a case study of nantong coal mine in Chongqing, China," Safety Science, vol. 122, Article ID 104515, 2020.

[21] C. Fan, S. Li, M. Luo, L. Zhou, H. Zhang, and Z. Yang, "Effects of $\mathrm{N}$ and $\mathrm{S}$ functionalities on binary gas co-adsorption on a coal macromolecule," Energy \& Fuels, vol. 33, no. 5, pp. 3934-3946, 2019.

[22] C. Fan, S. Li, D. Elsworth, J. Han, and Z. Yang, "Experimental investigation on dynamic strength and energy dissipation characteristics of gas outburst-prone coal," Energy Science \& Engineering, vol. 8, no. 4, pp. 1015-1028, 2020.

[23] C. Fan, M. Luo, S. Li, H. Zhang, Z. Yang, and Z. Liu, "A thermo-hydro-mechanical-chemical coupling model and its application in acid fracturing enhanced coalbed methane recovery simulation," Energies, vol. 12, no. 4, p. 626, 2019.

[24] Q. Jiang, B. Yang, F. Yan, L. Chang, Y. Shi, and L. Liu, "New method for characterizing the shear damage of natural rock joint based on 3D engraving and 3D scanning," International Journal of Geomechanics, vol. 20, no. 2, Article ID 06019022, 2020.

[25] W. S. Zhu, B. Sui, X. J. Li, S. C. Li, and W. T. Wang, "A methodology for studying the high wall displacement of large scale underground cavern complexes and it's applications," Tunnelling and Underground Space Technology, vol. 23, no. 6, pp. 651-664, 2008.

[26] C. Fei, J. Deng, C. He, W. Jinbing, and C. Gao, "Preliminary investigation on displacement prediction of large underground caverns," Chinese Rock Mechanics and Engineering, vol. 32, no. 4, pp. 747-752, 2013.

[27] T. Siren, P. Kantia, and M. Rinne, "Considerations and observations of stress-induced and construction-induced excavation damage zone in crystalline rock," International Journal of Rock Mechanics and Mining Sciences, vol. 73, pp. 165-174, 2015.

[28] M. Tao, Z.-X. Hong, K. Peng, P.-W. Sun, M.-Y. Cao, and K. Du, "Evaluation of excavation-damaged zone around 
underground tunnels by theoretical calculation and field test methods," Energies, vol. 12, no. 9, p. 1682, 2019.

[29] K. Suzuki, E. Nakata, M. Minami et al., "Estimation of the zone of excavation disturbance around tunnels, using resistivity and acoustic tomography," Exploration Geophysics, vol. 35, no. 1, pp. 62-69, 2004.

[30] L. Malmgren, D. Saiang, J. Töyrä, and A. Bodare, "The excavation disturbed zone (EDZ) at kiirunavaara mine, Swedenby seismic measurements," Journal of Applied Geophysics, vol. 61, no. 1, pp. 1-15, 2007.

[31] H. Zou and M. Xiao, "Study of methodology for assessment of excavation disturbed zone of underground caverns," Chinese Journal of Rock Mechanics and Engineering, vol. 29, no. 3, pp. 513-519, 2010.

[32] J. Zhang, J. Hu, Y. Yang, J. Wei, and J. Deng, "Acoustic velocity fitting and monitoring feedback analysis of surrounding rock loosing zone in underground powerhouse," Chinese Journal of Rock Mechanics and Engineering, vol. 30, no. 6, pp. 1191-1197, 2011.

[33] M. Hu, H. Zhou, Y. Zhang et al., "Acoustic emission monitoring on damage evolution of surrounding rock during headrace tunnel excavation by TBM," European Journal of Environmental and Civil Engineering, vol. 23, no. 10, pp. 1248-1264, 2017.

[34] G. Xu, J. Dong, Z. Li, S. Song, S. Zhang, and J. Wang, "EDZ assessmemnt for underground cavern by acoustic wave method," Earth Science-Journal of China University of Geosciences, vol. 39, no. 11, pp. 1599-1606, 2014.

[35] M. A. Perras and M. S. Diederichs, "Predicting excavation damage zone depths in brittle rocks," Journal of Rock Mechanics and Geotechnical Engineering, vol. 8, no. 1, pp. 60-74, 2016.

[36] J. Dong, G. Xu, Z. Li et al., "Classification of failure modes and controlling measures for surrounding rock of large-scale caverns with high geostress," Chinese Rock Mechanics and Engineering, vol. 33, no. 11, pp. 2161-2170, 2014.

[37] G. Xu, Z. Li, S. Song, W. Chen, S. Zhang, and J. Dong, "Assessment methods and criterion of EDZ for underground caverns," Journal of Central South University, vol. 48, no. 2, pp. 418-426, 2017.

[38] F. Wu, J. Liu, T. Liu, H. Zhuang, and C. Yan, "A method for assessment of excavation damaged zone (EDZ) of a rock mass and its application to a dam foundation case," Engineering Geology, vol. 104, no. 3-4, pp. 254-262, 2009. 